Research Paper

\title{
Melatonin Stimulates STAR Expression and Progesterone Production via Activation of the PI3K/AKT Pathway in Bovine Theca Cells
}

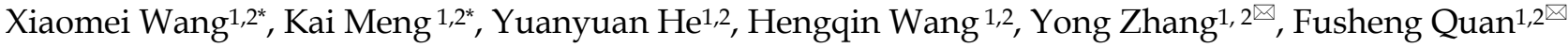 \\ 1. College of Veterinary Medicine, Northwest A\&F University, Yangling, Shaanxi, China \\ 2. Key Laboratory of Animal Bio-Technology, Ministry of Agriculture, Northwest A\&F University, Yangling, Shaanxi, China. \\ * These authors contributed equally to this research \\ $\triangle$ Corresponding authors: Fusheng Quan. Tel.: +86 29 87080092; Fax: +86 2987080085; Yong Zhang; Tel./Fax: +86 29 87080085; E-mail addresses: \\ quanfusheng@nwsuaf.edu.cn (F. Quan), zhangyong1956@nwsuaf.edu.cn (Y. Zhang).
}

(c) Ivyspring International Publisher. This is an open access article distributed under the terms of the Creative Commons Attribution (CC BY-NC) license (https://creativecommons.org/licenses/by-nc/4.0/). See http://ivyspring.com/terms for full terms and conditions.

Received: 2018.06.15; Accepted: 2018.12.03; Published: 2019.01.01

\begin{abstract}
Melatonin is present in mammalian follicular fluid and plays an important role in regulating steroidogenesis in follicular cells. In this study, we report the effect of melatonin on steroidogenesis in the theca interna (TI) in small bovine follicles and theca cells (TCs) cultured in vitro. Treatment with melatonin significantly increased the expression of steroidogenic acute regulatory protein (STAR) and the production of progesterone in both $\mathrm{TI}$ and in TCs. Melatonin stimulated the phosphorylation of AKT but not ERK1/2, and the addition of luzindole (a nonspecific MT1 and MT2 inhibitor) or 4P-PDOT (specific MT2 inhibitor) reduced melatonin-induced STAR expression, progesterone secretion, and PI3K/AKT pathway activation. The effect of melatonin on the $\mathrm{TI}$ in follicles was more obvious than on the TCs in vitro. Results indicate that melatonin stimulates the steroidogenesis of TCs mainly via the activation of the PI3K/AKT pathway by MT1 and MT2.
\end{abstract}

Key words: Melatonin; Theca cells; Steroidogenesis; PI3K/AKT; Bovine

\section{Introduction}

In mammals, melatonin (5-methoxy-Nacetyltryptamine) is mostly produced from the pineal gland, although enzymes for its synthesis are present widely in other organs as well [1]. Melatonin plays a vital role in the regulation of many important physiological activities that are related to circadian rhythm and reproduction [2]. It exists in the follicular fluid and has a dose-dependent effect on steroidogenesis and follicle growth [3]. Furthermore, melatonin can maintain normal follicle function and promote progesterone secretion [4].

Previous research has established that exogenous melatonin may improve the maturation of porcine oocytes [5] and modulate the steroidogenesis of ovarian theca cells (TCs) via its effects on the expression of cholesterol side-chain cleavage cytochrome P450 (CYP11A) and 17a-
hydroxylase/C17-20 lyase cytochrome P450 (CYP17A1) in porcine antral follicles [6]. In mammals, melatonin-mediated responses are principally exerted via native melatonin receptors, MT1 and MT2 [7]. Several studies have been performed on the effect of melatonin on granulosa cells (GCs). In porcine GCs in vitro, melatonin has been shown to mediate steroidogenesis predominantly via its membrane receptor MT2 [8]. In bovine GCs, melatoninstimulated progesterone production via both MT1 and MT2 [9]. On the basis of the expression of a luteinizing hormone receptor (LHR), steroidogenic acute regulatory protein (STAR), and steroidogenesis enzymes including $3 \beta$-hydroxysteroid dehydrogenase (HSD3B1), CYP11A1, and CYP17A1, the TCs of the theca interna (TI) synthesize androgens and progesterone. Although the effect of melatonin on the 
TCs of large bovine follicles $(8.0-22.0 \mathrm{~mm})$ has been reported by Feng et al. (2017), the specific regulationand signaling pathway-related molecular mechanisms of melatonin that affect TCs from small bovine follicles $(3.0-4.0 \mathrm{~mm})$ have not yet been clarified.

The PI3K/AKT and ERK1/2 signaling pathways play critical roles in the development and steroidogenesis of ovarian follicles [10]. In human GCs, TGF- $\beta 1$ was shown to decrease progesterone production and STAR expression via the ERK1/2 signaling pathway [11]. In bovine TCs, luteinizing hormone (LH) was shown to stimulate androgen production and CYP17A1 expression via the activation of the PI3K/AKT pathway [12]. Our previous study on goat follicle TCs also suggested that the PI3K/AKT pathway regulates steroidogenesis in TCs [13]. Several studies suggest that melatonin may regulate the activation of both of these pathways $[14,15,16]$. The basic framework of the PI3K and ERK1/2 pathways is well documented, but their influence on reproductive biology remains unclear. Despite their obvious importance, little attention has been paid on whether they are linked to the effects of melatonin on bovine TCs in small follicles.

Follicles contain follicular fluid and many types of cells that support oocyte growth and development until ovulation. The intricate network of communication between the oocyte, GCs, and TCs plays an important role in follicle formation and development. Furthermore, TCs, which synthesize androgens and progesterone and affect the function of GCs and oocytes [17], require multicellular interactions between the oocyte and GCs to maintain their function [18]. Ovarian steroid production is regulated by a complex signaling network between GCs and TCs. The results of previous studies have shown that treating TCs alone, GCs and TCs in coculture, or whole follicles has different effects on the function of TCs $[19,20,21]$. The present study aims to investigate the effects of melatonin on steroidogenesis in the TI in small follicles by treating small bovine follicles $(3.0-4.0 \mathrm{~mm})$ or isolated TCs, or TCs co-cultured with GCs in vitro using melatonin and to clarify whether the PI3K/AKT or ERK1/2 signaling pathways are involved in melatonin-induced steroidogenesis.

\section{Materials and Methods}

\section{Reagents}

For this study, DMEM/F12 medium, fetal bovine serum (FBS), BSA, and antibiotic-antimycotic solution were obtained from GIBCO (Grand Island, NY, USA).
Rabbit anti-FSHR and Goat anti-LHR antibodies were obtained from Santa Cruz Biotechnology (Santa Cruz, CA, USA). Rabbit anti-CYP17A1, anti-STAR, anti-HSD3B1 and anti-GAPDH antibodies were from Abcam (Cambridge, MA, USA). Rabbit anti-CYP11A1 was from Bioss (Woburn, MA, USA). Goat anti-rabbit secondary antibody, DAPI Staining Solution, protease inhibitors, QuickBlock ${ }^{\mathrm{TM}}$ Blocking Buffer for Western Blot and radioimmunoprecipitation assay buffer were obtained from Beyotime Institute of Biotechnology (Shanghai, China). Trizol reagent was obtained from Invitrogen (Carlsbad, CA, USA). SYBR PrimeScript reverse transcription-polymerase chain reaction (RT-PCR) Kit and SYBR Premix ExTaq II were from TaKaRa Inc (Shiga Prefecture, Japan). Coomassie brilliant blue was from TransGen Biotech (Beijing, China). Anti-total-AKT, anti-phospho-AKT, anti-total-ERK1/2 and anti-phospho-ERK1/2 antibodies were from Cell Signaling Technology, Inc (Beverly, MA). ELISA kit of progesterone was from Wuxi Donglin Sci \& Tech Development Co.,Ltd; (China). ELISA kit of androstenedione was from Cloud-Clone Corp., (Houston, USA). LY294002, wortmannin, luzindole and 4P-PDOT were from Sigma-Aldrich Inc., (St.Louis, MO, USA).

\section{Separation and selection of follicles}

A local abattoir in $\mathrm{Xi}^{\prime} \mathrm{An}$, China, provided bovine ovaries from slaughtered mature cows. Ovaries without large follicles $(>8 \mathrm{~mm})$ or corpus lutea were washed three times with PBS and then cultured in DMEM/F12 medium (GIBCO, Grand Island, NY, USA). Following Wang et al.'s procedure, the follicles $(3.0-4.0 \mathrm{~mm})$ were dissected using two surgical tweezers and then observed under a stereomicroscope (Nikon, Tokyo, Japan). Only follicles with highly vascularized theca, complete GC walls, and clear follicular fluid were selected for research [22]. We also chose medium $(5.0-6.0 \mathrm{~mm})$ and large $(>8.0 \mathrm{~mm})$ follicles from which to isolate the TI.

\section{Isolation and purification of TCs}

The follicles were cut into two halves by using two aseptic needles, and a stereomicroscope (Nikon) was used to peel away the TI. Thereafter, a scalpel was used to dislodge the GCs inside the TI. The GCs were pelleted by centrifugation $(1000 \times \mathrm{g}$ for $10.0 \mathrm{~min})$ in DMEM/F12 medium (GIBCO).

The TI was shaken three times in DMEM/F12 medium (GIBCO) and then minced for RNA extraction and TCs culture. We used the $1.0 \mathrm{mg} / \mathrm{mL}$ collagenase $(170.0 \mathrm{U} / \mathrm{mg}$, type 4 ; GIBCO) to isolate the TCs as described previously [13]. Thereafter, TCs were cultured in DMEM/F12 medium (GIBCO) in 24-well plastic plates (Corning Incorporated; Corning, 
NY, USA) with $10.0 \%$ FBS (GIBCO), $0.1 \%$ BSA (GIBCO), and $1 \%$ antibiotic-antimycotic solution (GIBCO).

The purity of TCs was evaluated as follows: TCs were incubated with rabbit anti-CYP17A1 (1:200; Abcam; Cambridge, MA, USA) and rabbit anti-FSHR (1:200; Santa Cruz Biotechnology; Santa Cruz, CA, USA) overnight at $4{ }^{\circ} \mathrm{C}$. After washing three times with PBS, TCs were incubated with Alexa Fluor 555-labeled goat anti-rabbit secondary antibody (1:500; Beyotime Institute of Biotechnology; Shanghai, China) at room temperature for $1 \mathrm{~h}$. Thereafter, TCs were washed three times with PBS and incubated again with DAPI staining solution (Beyotime Institute of Biotechnology) at room temperature for $3 \mathrm{~min}$. After washing the TCs three times with PBS, a fluorescence microscope (Nikon) was used to detect the TCs.

\section{Treatment of follicles and TCs}

One follicle was cultured per well in 24-well plastic plates (Corning Incorporated) with $1 \mathrm{~mL}$ DMEM/F12 medium (GIBCO) containing 1.0\% FBS (GIBCO), $\quad 0.1 \% \quad$ BSA (GIBCO), and $1 \%$ antibiotic-antimycotic solution (GIBCO). The follicles were treated with vehicle (0.01\% DMSO), different doses of melatonin or $\mathrm{LH}$ for $48 \mathrm{~h}$ with or without pretreatment with vehicle $(0.01 \% \mathrm{DMSO})$, or the inhibitors of PI3K (LY294002, wortmannin, Sigma) and MTRs (luzindole and 4P-PDOT, Sigma) for 30 min. The medium was removed every $24 \mathrm{~h}$. After $48 \mathrm{~h}$ of incubation, the medium was stored at $-20{ }^{\circ} \mathrm{C}$ by centrifugation $(1000 \times g$ for $20.0 \mathrm{~min})$. The TI was minced for RNA and protein isolation. All experiments were repeated three times for follicles from independent batches.

After being cultured for $48 \mathrm{~h}$, the TCs medium was replaced with DMEM/F12 medium (GIBCO) containing 1.0\% FBS (GIBCO) [23], 0.1\% BSA (GIBCO) and $1 \%$ antibiotic-antimycotic solution (GIBCO). The TCs were treated with vehicle $(0.01 \%$ DMSO) or melatonin for $48 \mathrm{~h}$ with or without pretreatment with vehicle $(0.01 \%$ DMSO $)$ or inhibitors of PI3K (LY294002, Sigma) and MTRs (luzindole and 4P-PDOT, Sigma) for $30 \mathrm{~min}$. The medium was removed every $24 \mathrm{~h}$. After $48 \mathrm{~h}$ of incubation, the medium was stored at $-20^{\circ} \mathrm{C}$ by centrifugation $(1000 \times$ $g$ for $20.0 \mathrm{~min}$ ). The TCs were used for RNA isolation. All the experiments were repeated three times for TCs from independent batches of follicles.

A coculture of GCs and TCs was established in a polyester membrane Transwell-clear insert (Corning Incorporated) as previously described [20]. Approximately $3 \times 10^{5}$ TCs were cultured alone or cocultured with $1 \times 10^{5}$ GCs from the same batch of follicles with vehicle (0.01\% DMSO) or melatonin for another $48 \mathrm{~h}$. The medium was removed every $24 \mathrm{~h}$. After $48 \mathrm{~h}$ of incubation, the medium was stored at -20 ${ }^{\circ} \mathrm{C}$ by centrifugation $(1000 \times g$ for $20.0 \mathrm{~min})$. The TCs were used for RNA isolation. All the experiments were repeated three times for TCs from independent batches of follicles.

\section{Hormone assays}

By using the respective ELISA kit according to the manufacturer's protocol, the concentrations of progesterone (Wuxi Donglin Sci \& Tech Development Co., Ltd.; China) and androstenedione (Cloud-Clone Corp., Houston, USA) in the liquid supernatant of the culture medium were determined. The inter- and intra- assay coefficients of variation $(\mathrm{CVs})$ were all $<12 \%$. All the experiments were repeated three times for TCs from independent batches of follicles.

\section{Reverse transcription and quantitative real-time polymerase chain reaction}

According to the manufacturer's instructions, total RNA was extracted from the TI and TCs by using Trizol reagent (Invitrogen, Carlsbad, CA, USA) and was reverse transcribed by the SYBR PrimeScript RT-PCR Kit (TaKaRa Inc., Shiga Prefecture, Japan). The cDNA was used for polymerase chain reaction (PCR) and Real-time quantitative PCR (RT-qPCR) analyses.

Table 1.Sequences for gene primers

\begin{tabular}{|c|c|c|}
\hline Gene & Primers (5'- 3') & The size of amplimers \\
\hline \multirow[t]{2}{*}{ STAR } & AGCTGGAAGACCCTCTCTAC & 164 \\
\hline & CACGTCAGGGATCACTTTACTC & \\
\hline \multirow[t]{2}{*}{ LHR } & АСТАТСАСТСАССТАТСТСССТАТС & 130 \\
\hline & GTTGTCAAAGGCATTAGCTTCTATC & \\
\hline \multirow[t]{2}{*}{ CYP11A1 } & AGACTTGGAGGGACCATGTA & 120 \\
\hline & GGATGCCTGGGTAATTCCTAAA & \\
\hline \multirow[t]{2}{*}{ CYP17A1 } & TTCTGAGCAAGGAAGTTCTGTTAG & 169 \\
\hline & TGCAGCAAGTTAGTGATGGAAT & \\
\hline \multirow[t]{2}{*}{ HSD3B1 } & CCATCATGAACGTCAATGTGAAAG & 93 \\
\hline & CTATGGTGCTGGTGTGGATAAA & \\
\hline \multirow[t]{2}{*}{ MT1 } & GGAGGGTGAAACCTGACGAC & 99 \\
\hline & CCCAGCAAATGGCAAAGAGG & \\
\hline \multirow[t]{2}{*}{ MT2 } & TAGCCTTGTACCCCTACCCG & 138 \\
\hline & CGATGGCGGTGATGTTGAAG & \\
\hline \multirow[t]{2}{*}{ GAPDH } & GTGAAGGTCGGAGTGAACGG & 245 \\
\hline & ATGTTGGCAGGATCTCGCTC & \\
\hline
\end{tabular}

The purpose of the PCR analyses was to assess the expressions of CYP17A1 and FSH receptor (FSHR) in the TI. Furthermore, the RT-qPCR analyses were used to assess the relative abundance of MT1, MT2, CYP11A1, CYP17A1, HSD3B1, STAR, and LHR mRNA. GAPDH was used as an internal control. Table 1 lists the specific primer sequences. The StepOne Plus PCR system (Applied Biosystems Inc., Carlsbad, CA, USA) was used for q-PCR using SYBR 
Premix Ex Taq II (TaKaRa Inc.) under the previously described conditions [13].

\section{Cell protein extracts and Western blot analyses}

The TI tissue was ground in a mortar, collected in $1.5 \mathrm{~mL}$ microfuge tubes, and lysed using radioimmunoprecipitation assay buffer (Beyotime Institute of Biotechnology) with $1 \times$ protease inhibitors (Beyotime Institute of Biotechnology) on ice for $30 \mathrm{~min}$.

Thereafter, the lysates were centrifuged at 13000 $\times \mathrm{g}$ for $15 \mathrm{~min}$, and the protein content was assayed using $20 \mu \mathrm{L}$ liquid supernatant with $200 \mu \mathrm{L}$ Coomassie brilliant blue (TransGen Biotech, Beijing, China) in 96-well plates (Corning Incorporated) at an absorbance of $595 \mathrm{~nm}$. The remaining supernatant samples were stored at $-80{ }^{\circ} \mathrm{C}$ after boiling in a water bath at $100{ }^{\circ} \mathrm{C}$ for $10 \mathrm{~min}$ with an equal volume of $2 \times$ SDS.

The samples were separated by $10 \%$ acrylamide sodium dodecyl sulfate polyacrylamide gel electrophoresis (SDS-PAGE) and transferred to polyvinylidene difluoride (PVDF) membranes. By using a slightly modified method, the PVDF membranes (Millipore, Bedford, MA, USA) were incubated with primary antibodies overnight at $4{ }^{\circ} \mathrm{C}$ after blocking in moderate blocking buffer (QuickBlock ${ }^{\mathrm{TM}}$ blocking buffer for western blot analysis, Beyotime Institute of Biotechnology) for 30 min [13]. The primary antibodies used were rabbit anti-total-AKT, rabbit anti-phospho-AKT, rabbit anti-total-ERK1/2, rabbit anti-phospho-ERK1/2 (1:1000, Cell Signaling Technology, Inc., Beverly, MA), rabbit anti-STAR, rabbit anti-CYP17A1, rabbit anti-HSD3B1, rabbit anti-GAPDH antibody (1:1000, Abcam), rabbit anti-CYP11A1 (1:500; Bioss), goat anti-LHR antibody (1:500; Santa) and incubated overnight at $4{ }^{\circ} \mathrm{C}$. A chemiluminescence reagent (BeyoECL Moon, Beyotime Institute of Biotechnology) was added to the membranes after incubation with the secondary goat anti-rabbit antibody and donkey anti-goat antibody (1:1000, Beyotime Institute of Biotechnology) for $2 \mathrm{~h}$, and analysis was performed using the ChemiDoc ${ }^{\mathrm{TM}} \mathrm{MP}$ Imaging System (BIO-RAD, USA) with Image Lab ${ }^{\mathrm{TM}}$ software. The membranes were cut to show the full area of the probed membrane.

\section{Statistical analyses}

All data were analyzed by one- or two-way analysis of variance using SPSS 20.0 (IBM Corporation, Armonk, NY, USA). The values are presented as means \pm S.E.M. Differences were considered significant when $P<0.05$ or $P<0.01$. All experiments were repeated three times by using independent follicle batches.

\section{Results}

\section{Effects of melatonin on steroidogenesis in TI in small follicles}

By using PCR analyses, we found that that CYP17A1 but not FSHR was expressed in TI (Fig. 1A), thus indicating that the TI was not mixed with GCs. According to real-time qPCR, the expression of MT1 and MT2 mRNA in the TI was markedly higher in small follicles than in medium or large follicles (Fig. 1B). Small follicles were treated for $48 \mathrm{~h}$ with different doses of melatonin or LH. There was a significant increase in progesterone production upon treatment with $10 \mathrm{ng} / \mathrm{mL}$ melatonin, but no effect was observed in other doses; however, androstenedione production was unaffected (Figs. 1E, F). Total RNA was extracted from the TI. The mRNA expression of MT1 and MT2 in the TI in small follicles significantly increased upon treatment with $10 \mathrm{ng} / \mathrm{mL}$ melatonin (Figs. 1C, D) or $0.1 \mathrm{IU} / \mathrm{mL} \mathrm{LH}$ (Figs. 2A, B). Additionally, LH increased CYP17A1 mRNA expression in the TI (Figs. $2 C)$.

Small follicles were treated with $10 \mathrm{ng} / \mathrm{mL}$ melatonin and $0.1 \mathrm{IU} / \mathrm{mL} \mathrm{LH}$ alone or in combination. The expression of STAR and LHR mRNA and protein was significantly increased by melatonin alone but increased further upon treatment with melatonin in combination with LH (Figs. 2D, H, I). Neither the combined treatment nor the melatonin alone significantly affected the CYP11A1, HSD3B1, or CYP17A1 mRNA and protein expression (Figs. 2E, F, $\mathrm{G}, \mathrm{I})$.

\section{Expression of STAR in different follicles}

RT-qPCR and western blotting were used to quantify the expression of STAR in TI of small (3.0-4.0 $\mathrm{mm})$, medium $(5.0-6.0 \mathrm{~mm})$ and large $(>8.0 \mathrm{~mm})$ follicles. STAR expression was markedly higher in small follicles than in medium and large follicles (Fig. $3)$.

\section{Role of MT1/MT2 in melatonin-induced regulation of steroidogenesis in $\mathrm{TI}$ in small follicles}

Small follicles were left untreated or were treated for $48 \mathrm{~h}$ with $10 \mathrm{ng} / \mathrm{mL}$ melatonin alone or in combination with the MTR inhibitors luzindole (a nonspecific inhibitor of MT1 and MT2) or 4P-PDOT (a specific MT2 inhibitor). Combined treatment with melatonin and luzindole significantly reduced the expression of MT1 and MT2 mRNA in the TI in small follicles, whereas 4P-PDOT treatment decreased only the MT2 mRNA expression (Fig. 4A). Combined 
A

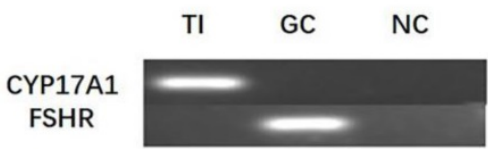

C

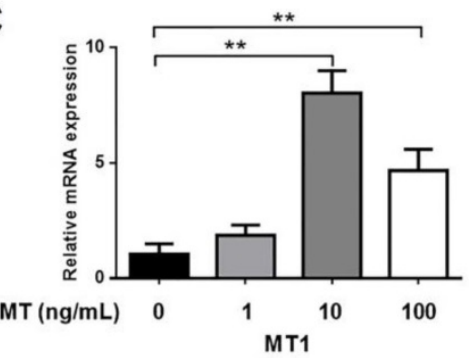

E

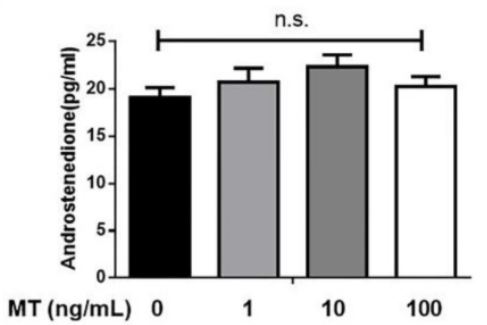

B

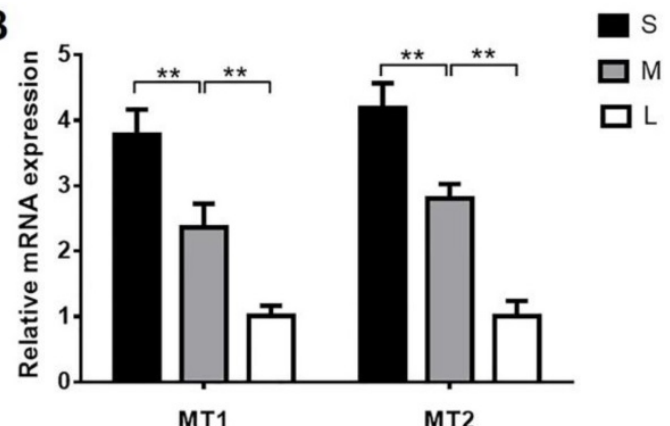

D

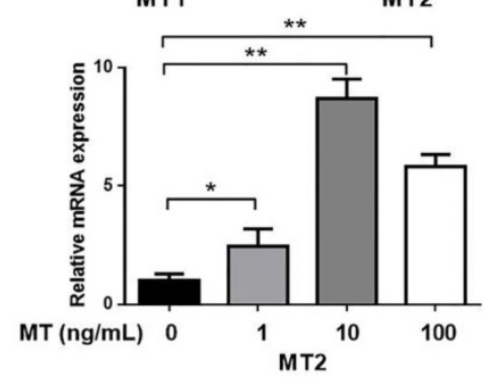

$\mathbf{F}$

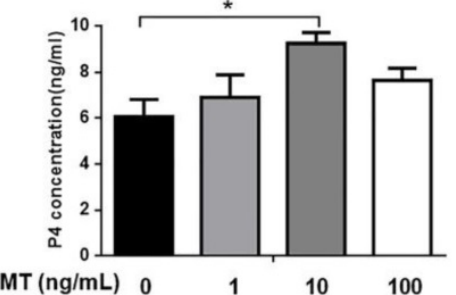

Figure 1. Dose-dependent effect of melatonin on TI in small follicles. (A) The expression of CYPI 7AI and FSHR was determined by PCR. (B) Differences in MTI and MT2 mRNA expression in TI of different follicles. Relative abundance of mRNA of (C) MTI and (D) MT2, and (E) production of androstenedione and (F) progesterone in small follicles. Total RNA was extracted from TI. The mRNA expression of MTI and MT2 was measured by RT-qPCR. The expression of GAPDH level was used as a standard. Small follicles were treated for $48 \mathrm{~h}$ with different doses of melatonin $(0,1,10,100 \mathrm{ng} / \mathrm{mL})$. The concentration of androstenedione and progesterone was measured by ELISA. The results are the mean \pm SEM of three independent experiments. $* P<0.05, * * P<0.01$. n.s.: not significant; S: small follicles; M: medium follicles; L: large follicles.

treatment with melatonin and luzindole significantly decreased the melatonin-mediated increases in progesterone production (Fig. 4B), as well as the STAR, LHR protein (Figs. 4C, D), and mRNA expressions (Figs. 4E, F), in the TI in small follicles. Treatment with 4P-PDOT decreased STAR and LHR expressions with no significant decrease in progesterone production.

\section{Effects of melatonin on the PI3K/AKT and MAPK- ERK $1 / 2$ pathways}

Treated the small follicles with $10 \mathrm{ng} / \mathrm{mL}$ melatonin, we investigated the phosphorylation of AKT and ERK1/2 in TI at different times from 0 to $4 \mathrm{~h}$. The phosphorylation of AKT peaked at $1 \mathrm{~h}$ (Fig. 5A) with no effect on MAPK activation (Fig. 5A). The treatment of small follicles with LY294002 or wortmannin (inhibitors of PI3K) inhibited melatonin-induced AKT phosphorylation in the TI with no effect on the total level of AKT protein (Figs.
5B, C). To investigate whether the activation of AKT by melatonin was required for MT1 or MT2 expression, we treated small follicles with melatonin alone or in combination with MTR inhibitors, luzindole, or 4P-PDOT for $1 \mathrm{~h}$. Melatonin combined with luzindole significantly decreased the melatonin-induced AKT phosphorylation in TI and the 4P-PDOT but with a lower inhibition ratio than luzindole (Fig. 5D).

\section{Effects of PI3K/AKT on the melatonin-induced upregulation of progesterone production and STAR expression in TI in small follicles}

Small follicles were left untreated or treated with $10 \mathrm{ng} / \mathrm{mL}$ melatonin alone or in combination with LY294002 or wortmannin for $48 \mathrm{~h}$. The addition of LY294002 or wortmannin significantly decreased melatonin-mediated increases in progesterone production and STAR mRNA and protein expressions in the TI (Fig. 6). 
A

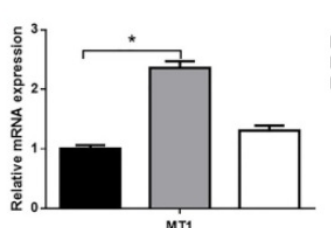

B

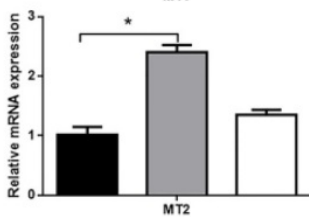

C

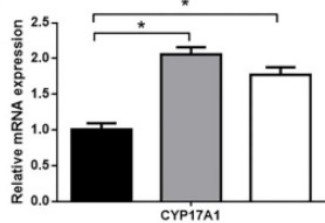

D

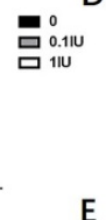

$\mathrm{E}$
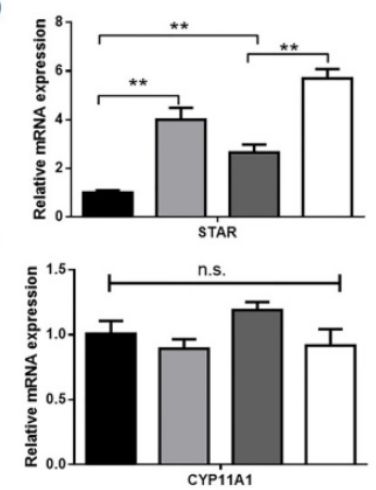

$\mathrm{F}$

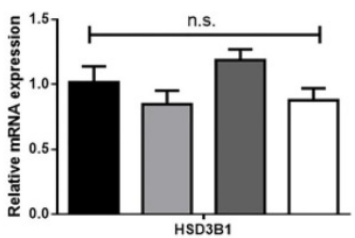

G

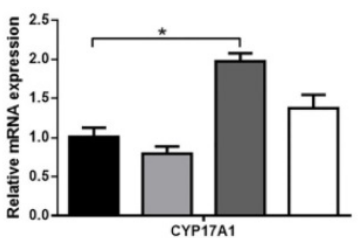

$\mathrm{H}$

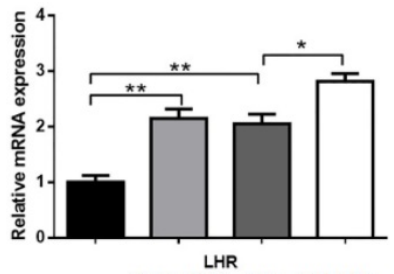

CON MT LH LH+MT

STAR

CYP11A1 - - -

HSD3B1

CYP17A1

LHR

GAPDH

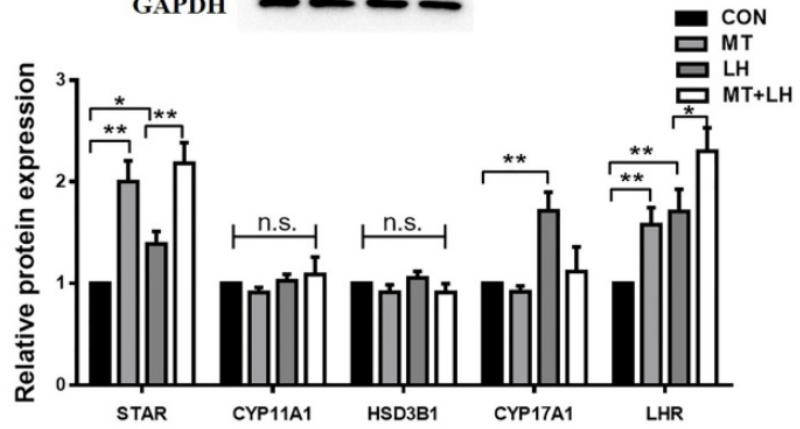

Figure 2. Effect of LH on relative abundance of mRNA of (A) MTI, (B)MT2, (C)CYPI7AI and melatonin-induced expression of (D-I) STAR, CYPIIA1, HSD3B 1, CYP17A1, LHR in TI. Small follicles were treated with different doses of LH $(0,0.1 \mathrm{IU}, 1 \mathrm{IU})$ or with $10 \mathrm{ng} / \mathrm{mL} \mathrm{melatonin}$ and $0.1 \mathrm{IU} / \mathrm{mL} \mathrm{LH}$ alone or in combination for $48 \mathrm{~h}$. Total RNA was extracted from TI. The mRNA expression of MTI, MT2, STAR, CYPI IAI, HSD3BI, CYPI 7AI and LHR was measured by RT-qPCR. GAPDH expression was used as a standard. TI lysates were subjected to SDS-PAGE/immunoblotting for STAR, CYP1 1A1, HSD3B1, CYP17A1, LHR and GAPDH analysis. The relative density ratio was calculated using a control group value of one. The results are the mean \pm SEM of three independent experiments. $* P<0.05$, $* * P<0.01$. n.s.: not significant.
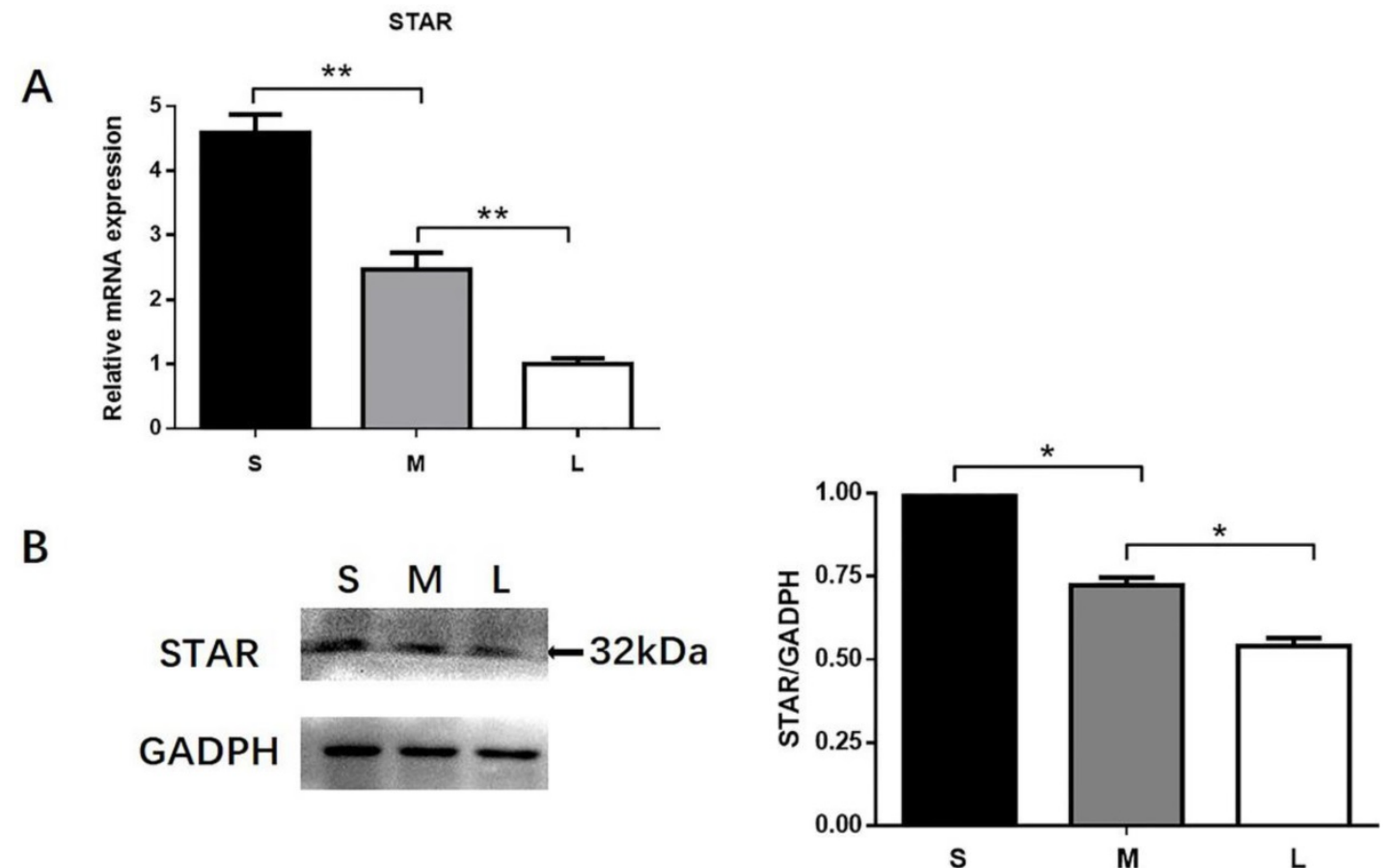

Figure 3. Differences in STAR expression in the TI of different follicles. TI was collected from small (3-4 mm), medium (5-6 mm), and large (>8 mm) follicles. Differences in STAR mRNA expression (A) and protein expression (B) in the TI of different follicles. STAR mRNA expression was determined by RT-qPCR. GAPDH expression was used as a standard. TI lysates were subjected to SDS-PAGE/immunoblotting for STAR and GAPDH analysis. The relative density ratio was calculated using a control group value of one. The results are the mean \pm SEM of three independent experiments. $* P<0.05$, $* * P<0.01$. S: small follicles; M: medium follicles; L: large follicles. 
A

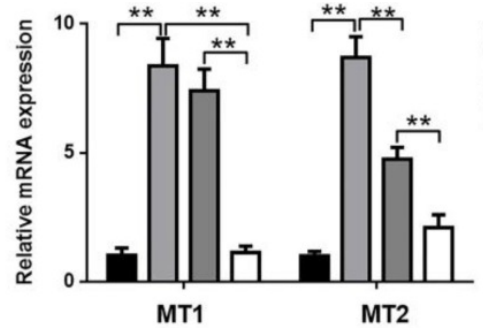

C

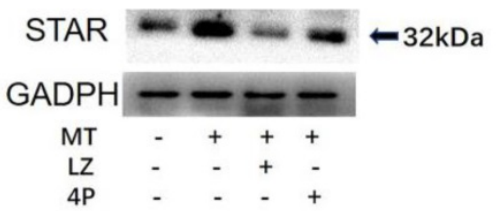

CON

MT

$\square$ MT+4P-PDOT

$\square \mathrm{MT}+$ Luzindole
B

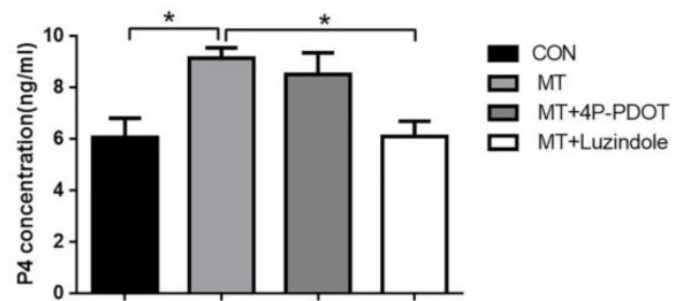

E STAR
D

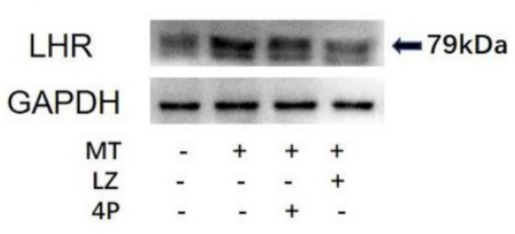

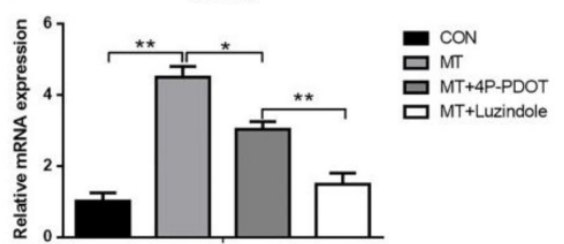
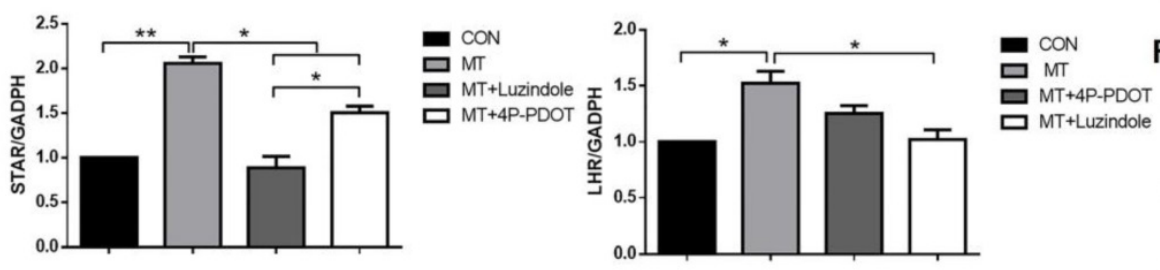

$\mathbf{F}$

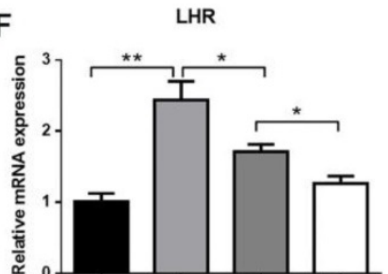

- CON

ㅁ MT

MT+4P-PDOT

口 MT+Luzindole

Figure 4. Role of MT1/MT2 receptors in the melatonin-induced expression of $\mathbf{M T I}$ and $\mathbf{M T 2}$ (A), production of progesterone (B), STAR protein and mRNA expressions (C, E), and LHR protein and mRNA expressions (D, F) in the TI in small follicles. Small follicles were treated with $10 \mathrm{ng} / \mathrm{mL}$ melatonin alone or in combination with MTR inhibitors, $10 \mu \mathrm{M}$ luzindole, or $10 \mu \mathrm{M}$ 4P-PDOT for $48 \mathrm{~h}$. Total RNA was extracted from the TI. The mRNA expressions of MTI, MT2, STAR, and LHR were measured by RT-qPCR. GAPDH expression was used as a standard. Progesterone concentration was measured by ELISA. TI lysates were subjected to SDS-PAGE/immunoblotting for STAR, $\mathrm{LHR}$, and GAPDH analyses. The relative density ratio was calculated using a control group value of one. The results are the mean \pm SEM of three independent experiments. *P $<0.05$, ** $P<0.01$.

A
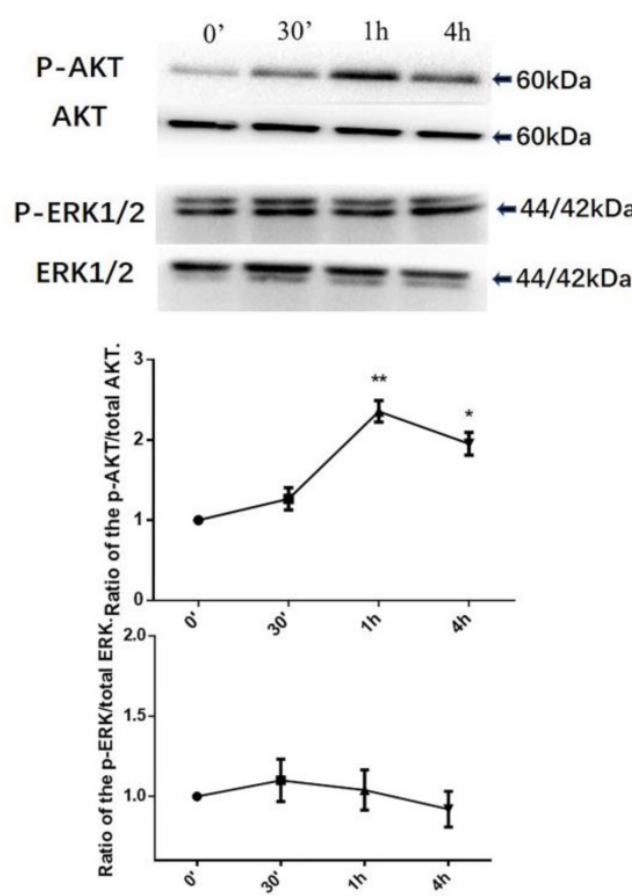

B
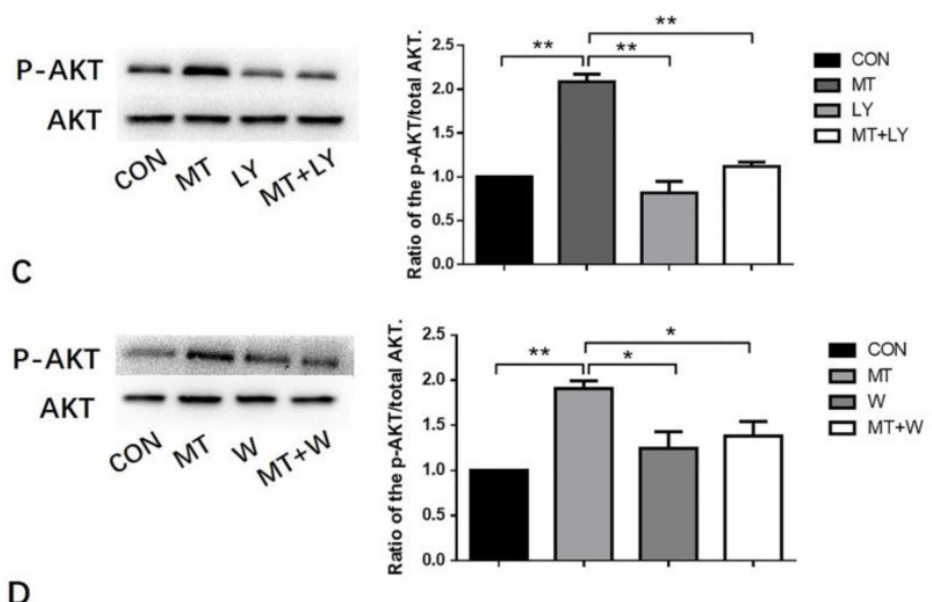

D
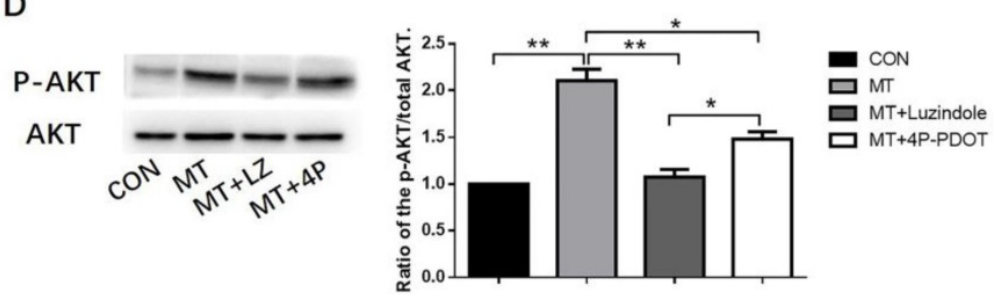

Figure 5. Effects of melatonin on the activation of the PI3K/AKT and MAPK- ERK1/2 pathways(A). Effect of inhibition of LY294002 and wortmannin on the activation of the PI3K/AKT pathway (B, C). Effect of MTR inhibitors on the activation of the PI3K/AKT pathway (D) in the TI in small follicles. Small follicles were treated with $10 \mathrm{ng} / \mathrm{mL}$ melatonin for $0 \mathrm{~min}, 30 \mathrm{~min}, 1 \mathrm{~h}$, or $4 \mathrm{~h}$ with or without pretreatment with a combination of inhibitors, $25 \mu \mathrm{M} L Y 294002,0.1 \mu \mathrm{M}$ wortmannin, $10 \mu \mathrm{M}$ luzindole, or 10 $\mu M 4$ P-PDOT for 30 min. TI lysates were subjected to SDS-PAGE/immunoblotting for P-AKT, total AKT, $\mathrm{P}-\mathrm{ERK} 1 / 2$, and total ERK1/2 analysis. The results are the mean \pm SEM of three independent experiments. The relative density ratio was calculated on the basis of a control group value of one. $* P<0.05$, $* * P<0.01$. LY: LY294002; W: wortmannin; LZ: luzindole; 4P: 4P-PDOT. 
A

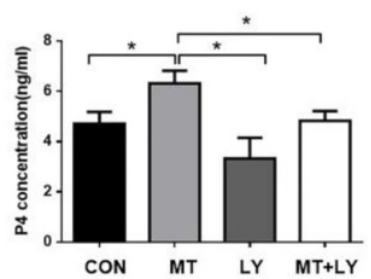

B

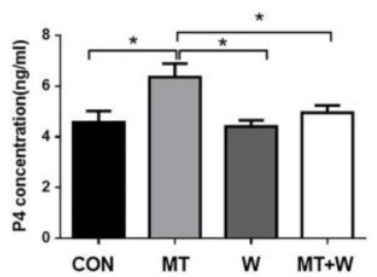

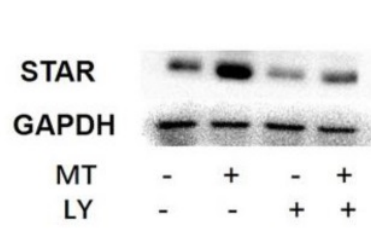

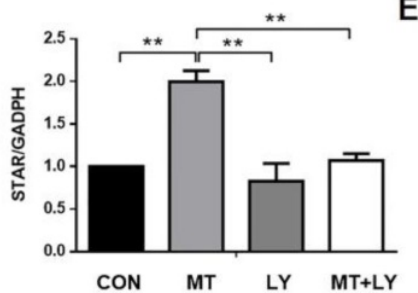

D
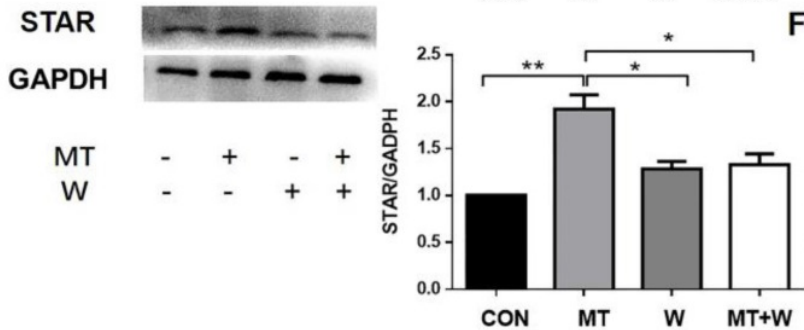
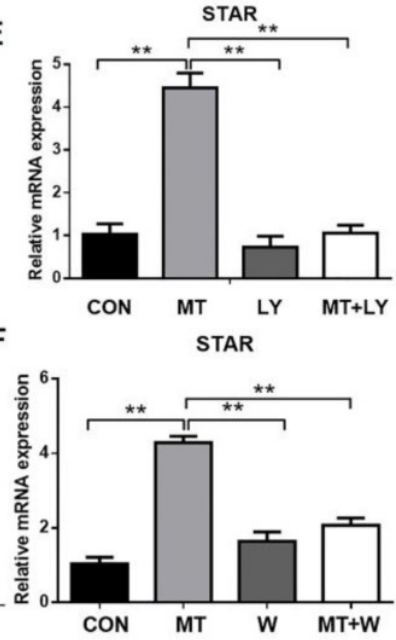

Figure 6. Role of the PI3K/AKT pathway in the melatonin-induced production of progesterone (A, B), STAR mRNA expression (E, F), and protein expression (C, D) in the TI in small follicles. Small follicles were treated for $48 \mathrm{~h}$ with $10 \mathrm{ng} / \mathrm{mL}$ melatonin alone or in combination with an inhibitor, $25 \mu \mathrm{M}$ LY294002 or $0.1 \mu \mathrm{M}$ wortmannin. Total RNA was extracted from TI. The mRNA expression of STAR was measured by RT-qPCR. GAPDH expression was used as a standard. Progesterone concentration was measured by ELISA. TI lysates were subjected to SDS-PAGE/immunoblotting for STAR and GAPDH analysis. The relative density ratio was calculated on the basis of a control group value of one. The results are the mean \pm SEM of three independent experiments. $* P<0.05, * * P<0.01$. LY: LY294002; W: wortmannin.

A

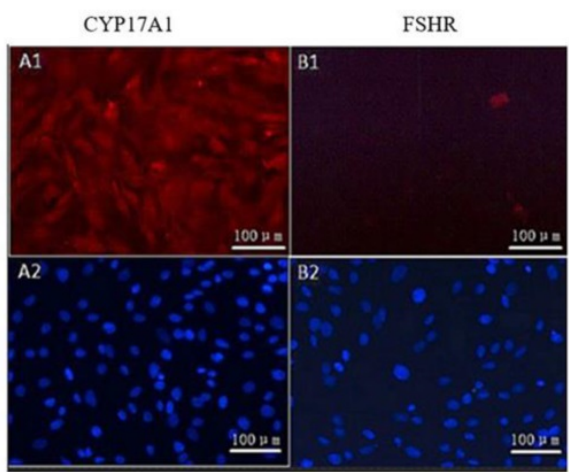

B

\begin{tabular}{rl}
\hline TCs (\%) & GCs (\%) \\
\hline $97.35 \pm 1.05$ & $2.3 \pm 0.9$ \\
\hline
\end{tabular}

C

D
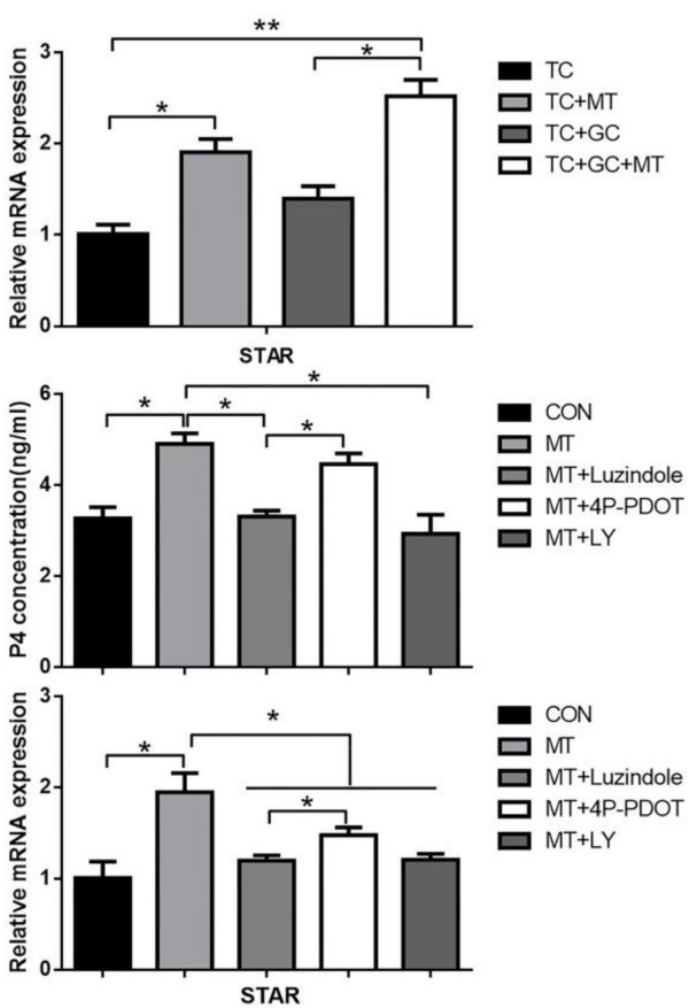

Figure 7. Effects of melatonin on the relative abundance of STAR mRNA and progesterone production in TCs. (A) Immunohistochemical analysis showed that the CYPI7A1 (A1), not the FSHR (B1), expressed in the TCs and DAPI (A2, B2) indicated the nucleus $(100 \times$, scale bar $=100 \mu \mathrm{m})$. (B) Immunohistochemical analysis indicated that TCs accounted for $97.35 \pm 1.05 \%$ of all cells. (C) TCs were untreated or treated with $10 \mathrm{ng} / \mathrm{mL}$ melatonin and cultured alone or cocultured with GCs for $48 \mathrm{~h}$. (D, E) TCs were treated with $10 \mathrm{ng} / \mathrm{mL}$ melatonin alone or in combination with inhibitors, $25 \mu \mathrm{M}$ LY294002, $10 \mu \mathrm{M}$ luzindole, or $10 \mu \mathrm{M} 4 \mathrm{P}-\mathrm{PDOT}$ for $48 \mathrm{~h}$. Total RNA was extracted from TCs. The mRNA expression of STAR was measured by RT-qPCR. GAPDH expression was used as a standard. Progesterone concentration was measured by ELISA. The results are the mean \pm SEM of three independent experiments. $* P<0.05, * * P<0.01$. LY: LY294002.

\section{Effects of melatonin on progesterone production and STAR expression in TCs in vitro}

On the basis of our observations on the effect of melatonin on the TI in small follicles, we investigated the ability of melatonin to induce steroidogenesis in TCs in vitro. First, we isolated TCs from small follicles and cultured them in vitro as described in the Materials and Methods section. Immunohistochemical analysis indicated that TCs accounted for $97.35 \pm 1.05 \%$ of all the cells (Figs. 7A, B).

TCs were left untreated or treated with melatonin for $48 \mathrm{~h}$ and were cultured either alone, or with GCs as described in the Materials and Methods 
section. Treated by melatonin when TCs were co-cultured with GC, the expression of STAR mRNA was significantly higher than when TCs were cultured alone (Fig. 7C). Furthermore, TCs were treated with melatonin for $48 \mathrm{~h}$ in the presence or absence of LY294002 or the MTR inhibitor luzindole or 4P-PDOT. Melatonin combined with luzindole or LY294002

\section{Discussion}

The estrous cycle of bovine has 2-3 follicular waves. Under the regulation of gonadotropin FSH and $\mathrm{LH}$, follicles undergo recruitment, selection and dominance processes until ovulation [24]. In a previous study, antral follicles that are less than $4 \mathrm{~mm}$ in diameter were assumed to be responsive to but independent of gonadotropin [25]. Follicles greater than $4 \mathrm{~mm}$ in diameter depend on gonadotropins for the recruitment $(4-5 \mathrm{~mm})$, selection, and dominance processes $(>8 \mathrm{~mm})$. Several reports have shown that melatonin exists in the follicular fluid and that MTRs (MT1 and MT2) are expressed in various types of ovarian cells [26,27]. Performing a comparison of melatonin concentration and receptor expression in follicles with different sizes is useful for understanding the role of melatonin in follicular development. It has previously been reported that the concentration of melatonin decreased with the follicle diameter increase in porcine follicular fluid [5]. Furthermore, TCs also contain the membrane receptors MT1 and MT2, which are expressed at higher levels in secondary follicle TCs than in tertiary follicle TCs. The present study first sought to determine the expression of MT1 and MT2 in the TI of bovine follicles with different sizes. The receptor expression was markedly higher in small follicles than in medium or large follicles. These results suggest that melatonin may affect the function of TCs in small follicles.

A two-cell, two-gonadotropin model has been used to explain the role of TCs and GCs in steroidogenesis [28]. Under the regulation of LH, cells in the TI express genes that are involved in steroidogenesis, including STAR, CYP11A1, CYP17A1 and HSD3B1, which regulate the production of androstenedione and progesterone. For the present study, we selected small follicles $(3.0-4.0 \mathrm{~mm}$ ) that are assumed to be in the gonadotropin-independent stage [20]; thus, we did not add FSH to the follicular medium [6]. The second question in this study sought to determine the effect of melatonin on TI steroidogenesis in small follicles. Unlike previous studies, the present research sought first to study the effect of melatonin on TI steroidogenesis in the follicular environment by treating small follicles with melatonin. In agreement with previous studies, significantly decreased the melatoninmediated increases in progesterone production and STAR mRNA expression in TCs (Figs. 7D, E). As shown above, 4P-PDOT treatment also decreased STAR expression with a lower inhibition ratio than luzindole. However, 4P-PDOT treatment did not affect progesterone production in TCs.

melatonin significantly increased MT1 and MT2 expressions and progesterone production in a dose-dependent manner [3,6,9,29]. However, androstenedione production was not significantly increased by melatonin possibly because CYP17A1 expression is unaffected by melatonin or because androstenedione is used for estradiol synthesis by GCs in small follicles. By contrast, Adriaens et al. (2006) found that melatonin increased androstenedione secretion in mouse follicles. This difference might be explained in part by the differences in species and the cell culture conditions which could have greatly affected the findings.

In the experiments, both MT1 and MT2 mRNA expressions were significantly increased after treatment with LH. This finding is contrary to those of previous studies that found that only MT1 mRNA expression was significantly increased after treatment with LH [30]. This difference might also be explained in part by the differences in species and experimental treatments. The present study did show a certain degree of inhibition of but not a significant decrease in CYP17A1 and CYP11A1 mRNA expressions in TI treated with melatonin, in contrast to an earlier study on the TI of porcine follicles [6]. This result may also be explained by the differences in species and melatonin dose.

The STAR protein transports cholesterol into the mitochondria in TCs, and this process is a key rate-limiting step in the initialization of the steroidogenesis process [32]. LH plays an important role in follicular development and luteinization by binding to its receptor, namely, LHR. One interesting finding from the present study is that STAR and LHR mRNA and protein expressions were significantly increased by treatment with melatonin alone and were further increased upon treatment with melatonin in combination with LH. A possible explanation for this might be that the mRNA expression of MTRs was increased by LH. This supports a previous observation that melatonin significantly increased STAR and LHR expressions in sheep germ cells [31]. Similar results have been previously observed in bovine GCs wherein melatonin significantly promoted LHR expression and progesterone secretion $[33,34]$. This finding is consistent with that of Nakamura [35], who observed that melatonin treatment increased the expression of 
the STAR gene, which was decreased by BMP-6. Another important finding of the present study was that the expression of STAR decreases as the diameter of the follicle increases; this result is consistent with the trend observed in MTRs. This finding supports the hypothesis that melatonin regulates the function of STAR in TCs, which may be the reason that melatonin promotes progesterone synthesis.

Melatonin acts mainly via the membrane receptors MT1 and/or MT2, both of which are G protein-coupled receptors [36]. MT1 and MT2 can form homo- and heterodimers, and MT1 can also interact with other membrane proteins to enhance or inhibit the activity of downstream signaling pathways [16]. Luzindole is a competitive MT2 receptor antagonist that inhibits the expression of MT1 and MT2, and 4P-PDOT is a selective MT2 receptor antagonist [2]. Similar to the present study, previous studies used only luzindole and 4P-PDOT to inhibit MT1 and MT2 expression to research the function of MTRs [14,37,38,39]. Therefore, luzindole and 4P-PDOT were used as melatonin receptor inhibitors in this study. The expression of STAR and LHR decreased with the addition of luzindole or 4P-PDOT. In agreement with a previous study on the corpus lutea of pregnant sows, melatonin-stimulated STAR expression via MT1 and MT2 [40]. However, the inhibition of both MT1 and MT2 (but not MT2 alone) inhibited the effect of melatonin on progesterone production in small follicles in the present study. This result may be explained in part by the complex downstream signaling pathways regulated by MT1 and MT2.

Thereafter, this study sought to determine the effect of MTRs and their downstream signaling pathways on TI steroidogenesis in small follicles. The PI3K and MAPK pathways are two major signaling pathways that are regulated by melatonin in follicular cells [12]. In the present study, melatonin activated the PI3K pathway without affecting the phosphorylation of ERK1/2; thus, we chose the PI3K/AKT pathway as the subject of our study and did not perform subsequent experiments with an ERK1/2 pathway inhibitor. This result was similar to that of previous reports on mouse GCs [30]. LY294002 and wortmannin were used as specific inhibitors of the PI3K/AKT pathway in this study. By inhibiting the PI3K via LY294002 or wortmannin, we found that the melatonin-stimulated STAR expression and progesterone production were significantly decreased. These results were consistent with those of earlier studies [41,42]. Furthermore, we found that the inhibition of MT1 and MT2 or MT2 alone inhibited AKT phosphorylation, thus indicating that melatonin activated the AKT pathway via MT1 and MT2. These results are consistent with the result that melatonin regulates the function of bovine GCs and sertoli cells via MT1 and MT2 in previous studies $[9,29]$. In mouse GCs, pancreatic islets, and embryonic stem cells, melatonin activated the AKT pathway via MT1 $[14,30,43]$. A possible explanation for this may be that MT2 was abundantly present only in TCs even though MT1 was reported to be highly expressed in TCs and GCs [44]. This means that MT2 may play an important role in TCs. We did not detect the activation of the ERK pathway, and this finding may be related to the melatonin concentration we used and the fact that the expression of MTRs and the signaling pathways that they regulate vary among tissues and cells [45]. On the basis of our data, we can infer that melatonin-stimulated STAR expression in the TI and that progesterone production in small follicles may occur via the activation of the PI3K/AKT pathway via MT1 and MT2.

The findings above show the effect of melatonin on the TI of small follicles. STAR expression may be somewhat influenced by other follicular cells, and the contents of the follicular fluid. The above tests detected the progesterone secreted by follicles, but GCs interfered with the results. Thus, we assessed the effect of melatonin in TCs cultured in vitro. As previously reported [46,47], we used CYP17A1 and FSHR as marker genes for TCs. The results of the present study indicate that when TCs were cultured alone, STAR expression was increased by melatonin to a similar degree, similar to that when TCs were cocultured with GCs. In agreement with a previous study of goat TCs, coculture with GCs did not significantly increase the expression of steroidogenic genes in TCs [20]. In a previous study on bovine TCs from large follicles $(8.0-22.0 \mathrm{~mm})$, melatonin inhibited the LH+IGF1-induced expression of STAR mRNA [48]. A possible explanation for this might be that the melatonin concentration used $(10 \mathrm{mM}=2.3 \mu \mathrm{g} / \mathrm{mL})$ was much higher than that used in the present study $(10 \mathrm{ng} / \mathrm{mL}$ ). Alternatively, the discrepancy could be attributed to different follicular development stages and the effect of LH and IGF1 on the function of melatonin. Surprisingly, in the present study, STAR expression in the TI was significantly increased (4.31-fold) by melatonin; this was a significantly greater increase than when TCs were treated in vitro with melatonin, as shown above. Similarly, it was previously observed in mouse GCs that the MT1 surges in vivo were significantly higher than those in vitro [30]. There are several possible explanations for this result: it may not be possible to simulate the follicular environment in vitro, or other follicle cells or follicular fluid components may affect the function of melatonin. Finally, the present research aimed to 
determine the effect of melatonin on progesterone production and STAR expression in TCs in vitro. Melatonin was found to stimulate STAR expression and progesterone production in TCs in vitro possibly via the activation of the PI3K/AKT pathway by MT1 and MT2. This finding indicates that the effect of melatonin on TCs cultured in vitro is essentially the same as that on the TI in small follicles.

In summary, the present study aimed to demonstrate of the effects of melatonin on TI steroidogenesis in bovine small follicles and TCs cultured in vitro, and also the specific regulation mechanisms. The results indicated that melatonin stimulates STAR expression and progesterone production in TCs via the activation of the PI3K/AKT pathway by MT1 and MT2. One interesting finding was that the effect of melatonin on the TI in follicles was more obvious than that on TCs in vitro. This result may be related to the enhanced regulation of melatonin by other follicle cells or follicular fluid components. Our findings support the key role of melatonin in the regulation of TC steroidogenesis. Further research should be undertaken to investigate potential mediators in follicular fluid that could affect the function of melatonin.

\section{Abbreviations}

TCs: theca cells; GCs: granulosa cells; MTR: melatonin receptor; TI: theca interna; CYP11A: cholesterol side-chain cleavage cytochrome P450; CYP17A1: 17a-hydroxylase/C17-20 lyase cytochrome P450; STAR: steroidogenic of the acute regulatory protein; HSD3B1: 3 $\beta$-hydroxysteroid dehydrogenase; CL: corpus luteum; FBS: fetal bovine serum; RT-PCR: reverse transcription-polymerase chain reaction; FSHR: FSH receptor; LHR: Luteinizing hormone receptor; SDS-PAGE: sodium dodecyl sulfate polyacrylamide gel electrophoresis; PVDF: polyvinylidene difluoride.

\section{Acknowledgments}

This research was supported by grants from National Major Project (NO.2016ZX08007-002) and Shaanxi Province Agricultural Program for Science and Technology Development (2014K02-07-02).

\section{Competing Interests}

The authors have declared that no competing interest exists.

\section{References}

1. Singh M, Jadhav HR. Melatonin: functions and ligands. Drug Discov Today. 2014; 19: 1410-8.

2. Emet M, Ozcan H, Ozel L, Yayla M, Halici Z, Hacimuftuoglu A. A Review of Melatonin, Its Receptors and Drugs. Eurasian J Med. 2016; 48: 135-41.
3. Adriaens I, Jacquet P, Cortvrindt R, Janssen K, Smitz J. Melatonin has dose-dependent effects on folliculogenesis, oocyte maturation capacity and steroidogenesis. Toxicology. 2006; 228: 333-43.

4. Maganhin CC, Fuchs LF, Simoes RS, Oliveira-Filho RM, de Jesus Simoes M, Baracat EC, et al. Effects of melatonin on ovarian follicles. Eur J Obstet Gynecol Reprod Biol. 2013; 166: 178-84.

5. Shi JM, Tian XZ, Zhou GB, Wang L, Gao C, Zhu SE, et al. Melatonin exists in porcine follicular fluid and improves in vitro maturation and parthenogenetic development of porcine oocytes. Journal of pineal research. 2009; 47: 318-23.

6. Tanavde V, Maitra A. In vitro modulation of steroidogenesis and gene expression by melatonin: a study with porcine antral follicles. Endocrine research. 2003; 29: 399-410.

7. Dubocovich ML, Markowska M. Functional MT1 and MT2 melatonin receptors in mammals. Endocrine. 2005; 27: 101-10.

8. He YM, Deng HH, Shi MH, Bodinga BM, Chen HL, Han ZS, et al. Melatonin modulates the functions of porcine granulosa cells via its membrane receptor MT2 in vitro. Anim Reprod Sci. 2016; 172: 164-72.

9. Wang SJ, Liu WJ, Wu CJ, Ma FH, Ahmad S, Liu BR, et al. Melatonin suppresses apoptosis and stimulates progesterone production by bovine granulosa cells via its receptors (MT1 and MT2). Theriogenology. 2012; 78: 1517-26.

10. Dupont J, Reverchon M, Cloix L, Froment P, Rame C. Involvement of adipokines, AMPK, PI3K and the PPAR signaling pathways in ovarian follicle development and cancer. Int J Dev Biol. 2012; 56: 959-67.

11. Fang L, Chang HM, Cheng JC, Leung PC, Sun YP. TGF-beta1 downregulates StAR expression and decreases progesterone production through Smad3 and ERK1/2 signaling pathways in human granulosa cells. J Clin Endocrinol Metab. 2014; 99: E2234-43.

12. Fukuda S, Orisaka M, Tajima K, Hattori K, Kotsuji F. Luteinizing hormone-induced Akt phosphorylation and androgen production are modulated by MAP Kinase in bovine theca cells. J Ovarian Res. 2009; 2: 17.

13. Wang X, Zou P, He Y, Meng K, Quan F, Zhang Y. Effect of luteinizing hormone on goat theca cell apoptosis and steroidogenesis through activation of the PI3K/AKT pathway. Anim Reprod Sci. 2018; 190: 108-18.

14. Picinato MC, Hirata AE, Cipolla-Neto J, Curi R, Carvalho CR, Anhe GF, et al. Activation of insulin and IGF-1 signaling pathways by melatonin through MT1 receptor in isolated rat pancreatic islets. J Pineal Res. 2008; 44: 88-94.

15. Kilic U, Kilic E, Reiter RJ, Bassetti CL, Hermann DM. Signal transduction pathways involved in melatonin-induced neuroprotection after focal cerebral ischemia in mice. J Pineal Res. 2005; 38: 67-71.

16. Hardeland R. Melatonin: signaling mechanisms of a pleiotropic agent. Biofactors. 2009; 35: 183-92.

17. Young J, McNeilly AS. Theca: the forgotten cell of the ovarian follicle. Reproduction. 2010; 140: 489-504.

18. Liu C, Peng J, Matzuk MM, Yao HH-C. Lineage specification of ovarian theca cells requires multicellular interactions via oocyte and granulosa cells. Nature communications. 2015; 6

19. Hoang YD, McTavish KJ, Chang RJ, Shimasaki S. Paracrine regulation of theca androgen production by granulosa cells in the ovary. Fertil Steril. 2013; 100: $561-7$.

20. Qiu M, Quan F, Han C, Wu B, Liu J, Yang Z, et al. Effects of granulosa cells on steroidogenesis, proliferation and apoptosis of stromal cells and theca cells derived from the goat ovary. J Steroid Biochem Mol Biol. 2013; 138: 325-33.

21. Orisaka M, Tajima K, Mizutani T, Miyamoto K, Tsang BK, Fukuda S, et al. Granulosa cells promote differentiation of cortical stromal cells into theca cells in the bovine ovary. Biol Reprod. 2006; 75: 734-40.

22. Mani AM, Fenwick MA, Cheng Z, Sharma MK, Singh D, Wathes DC. IGF1 induces up-regulation of steroidogenic and apoptotic regulatory genes via activation of phosphatidylinositol-dependent kinase/AKT in bovine granulosa cells. Reproduction. 2010; 139: 139-51.

23. Komatsubara M, Hara T, Hosoya T, Toma K, Tsukamoto-Yamauchi N, Iwata $\mathrm{N}$, et al. Melatonin regulates catecholamine biosynthesis by modulating bone morphogenetic protein and glucocorticoid actions. J Steroid Biochem Mol Biol. 2017; 165: 182-9.

24. Aerts JM, Bols PE. Ovarian follicular dynamics. A review with emphasis on the bovine species. Part II: Antral development, exogenous influence and future prospects. Reprod Domest Anim. 2010; 45: 180-7.

25. Orisaka M, Mizutani T, Tajima K, Orisaka S, Shukunami K, Miyamoto K, et al. Effects of ovarian theca cells on granulosa cell differentiation during gonadotropin-independent follicular growth in cattle. Mol Reprod Dev. 2006; 73: $737-44$

26. Tamura H, Takasaki A, Taketani T, Tanabe M, Kizuka F, Lee L, et al. The role of melatonin as an antioxidant in the follicle. Journal of ovarian research. 2012; 5. 5 .

27. Reiter RJ, Tan DX, Tamura H, Cruz MH, Fuentes-Broto L. Clinical relevance of melatonin in ovarian and placental physiology: a review. Gynecol Endocrinol. 2014; 30: 83-9.

28. Drummond AE. The role of steroids in follicular growth. Reproductive Biology and Endocrinology. 2006; 4: 16.

29. Yang WC, Tang KQ, Fu CZ, Riaz H, Zhang O, Zan LS. Melatonin regulates the development and function of bovine Sertoli cells via its receptors MT1 and MT2. Anim Reprod Sci. 2014; 147: 10-6.

30. He C, Ma T, Shi J, Zhang Z, Wang J, Zhu K, et al Melatonin and its receptor MT1 are involved in the downstream reaction to luteinizing hormone and participate in the regulation of luteinization in different species. Journal of pineal research. 2016; 61: 279-90. 
31. Deng SL, Chen SR, Wang ZP, Zhang Y, Tang JX, Li J, et al. Melatonin promotes development of haploid germ cells from early developing spermatogenic cells of Suffolk sheep under in vitro condition. J Pineal Res. 2016; 60: 435-47.

32. Manna PR, Dyson MT, Stocco DM. Regulation of the steroidogenic acute regulatory protein gene expression: present and future perspectives. Molecular human reproduction. 2009; 15: 321-33.

33. Wang SJ, Liu WJ, Wang LK, Pang XS, Yang LG. The role of Melatonin receptor MTNR1A in the action of Melatonin on bovine granulosa cells. Mol Reprod Dev. 2017; 84: 1140-54.

34. Wang S, Liu W, Pang X, Dai S, Liu G. The Mechanism of Melatonin and Its Receptor MT2 Involved in the Development of Bovine Granulosa Cells. Int J Mol Sci. 2018; 19: 2028.

35. Nakamura E, Otsuka F, Terasaka $T$, Inagaki $K$, Hosoya $T$, Tsukamoto-Yamauchi N, et al. Melatonin counteracts BMP-6 regulation of steroidogenesis by rat granulosa cells. The Journal of steroid biochemistry and molecular biology. 2014; 143: 233-9.

36. Slominski RM, Reiter RJ, Schlabritz-Loutsevitch N, Ostrom RS, Slominski AT. Melatonin membrane receptors in peripheral tissues: distribution and functions. Mol Cell Endocrinol. 2012; 351: 152-66.

37. Bazwinsky-Wutschke I, Wolgast S, Muhlbauer E, Albrecht E, Peschke E. Phosphorylation of cyclic AMP-response element-binding protein (CREB) is influenced by melatonin treatment in pancreatic rat insulinoma beta-cells (INS-1). J Pineal Res. 2012; 53: 344-57.

38. Pires-Lapa MA, Tamura EK, Salustiano EM, Markus RP. Melatonin synthesis in human colostrum mononuclear cells enhances dectin-1-mediated phagocytosis by mononuclear cells. J Pineal Res. 2013; 55: 240-6.

39. Zibolka J, Muhlbauer E, Peschke E. Melatonin influences somatostatin secretion from human pancreatic delta-cells via MT1 and MT2 receptors. J Pineal Res. 2015; 58: 198-209.

40. Zhang W, Wang Z, Zhang L, Zhang Z, Chen J, Chen W, et al. Melatonin stimulates the secretion of progesterone along with the expression of cholesterol side-chain cleavage enzyme (P450scc) and steroidogenic acute regulatory protein (StAR) in corpus luteum of pregnant sows. Theriogenology. 2018; 108: 297-305.

41. Palaniappan $\mathrm{M}$, Menon KM. Luteinizing hormone/human chorionic gonadotropin-mediated activation of mTORC1 signaling is required for androgen synthesis by theca-interstitial cells. Mol Endocrinol. 2012; 26: $1732-42$.

42. Chen YJ, Hsiao PW, Lee MT, Mason JI, Ke FC, Hwang JJ. Interplay of PI3K and cAMP/PKA signaling, and rapamycin-hypersensitivity in TGFbeta1 enhancement of FSH-stimulated steroidogenesis in rat ovarian granulosa cells. J Endocrinol. 2007; 192: 405-19.

43. Wu H, Song C, Zhang J, Zhao J, Fu B, Mao T, et al. Melatonin-mediated upregulation of GLUT1 blocks exit from pluripotency by increasing the uptake of oxidized vitamin C in mouse embryonic stem cells. Faseb j. 2017; 31: 1731-43.

44. Somenath G, Chandana H. Histology and Immunohistochemical Localization of Different Hormone Receptors (MT1, MT2, AR, GR, Era) in Various Organs (Spleen, Thymus, Ovary, Uterus and Testes) of Indian Goat C. Hircus., International Journal of Research Studies in Biosciences. 2018; 7: 1-13.

45. Pandi-Perumal SR, Trakht I, Srinivasan V, Spence DW, Maestroni GJ, Zisapel

$\mathrm{N}$, et al. Physiological effects of melatonin: role of melatonin receptors and signal transduction pathways. Progress in neurobiology. 2008; 85: 335-53.

46. Hatzirodos N, Hummitzsch K, Irving-Rodgers HF, Rodgers RJ. Transcriptome comparisons identify new cell markers for theca interna and granulosa cells from small and large antral ovarian follicles. PLoS One. 2015; 10: e0119800.

47. Romereim SM, Summers AF, Pohlmeier WE, Zhang P, Hou X, Talbott HA, et al. Gene expression profiling of bovine ovarian follicular and luteal cells provides insight into cellular identities and functions. Mol Cell Endocrinol. 2017; 439: 379-94.

48. Feng T, Schutz LF, Morrell BC, Perego MC, Spicer LJ. Effect of melatonin on bovine theca cells in vitro. Reprod Fertil Dev. 2017; 30: 643-50. 